\title{
Effect of Housing on General Behaviour, Performance and Health of Dairy Animals-A Review
}

\author{
Komal $^{1}$, Sweety ${ }^{2}$, Veenesh Rajpoot ${ }^{3}$ and Man Singh ${ }^{1}$ \\ ${ }^{1}$ Department of Livestock Production Management, LUVAS, Hisar, India \\ ${ }^{2}$ Department of Veterinary Physiology \& Biochemistry, LUVAS, Hisar, India \\ ${ }^{3}$ Livestock Production Management, National Dairy Research Institute, Karnal, India \\ *Corresponding author
}

Keywords

Calves, health, behaviour, social

Article Info

Accepted:

20 January 2020

Available Online:

10 February 2020

\section{A B S T R A C T}

Social facilitation defined as initiation of a particular response while observing others engaged in that behavior. Contact with the dam or other older animals within the first few weeks of life able to learn young animals to start sampling solid feeds and to eat. Social facilitation and social learning may result in higher intake of solid feed and improved body weight gains compared with individually housed calves. Many researchers reported that calves housed in group showed more eating and lying time but lesser abnormal behaviour like cross-sucking, self- licking, tongue rolling etc. Group housed calves performed more health problems mainly, diarrhea, respiratory as compared to individual housed calves. After weaning, socially housed calves performed better as compared to individually housed calves. So overall, social environment is must for overall development and welfare of calves.

\section{Introduction}

Effect of housing on general behaviour of calves

Mahmoud and Darwish. (2018) found that buffalo calves housed in pair group showed more $(\mathrm{P} \leq 0.05)$ eating and drinking, chewing/ruminating, object manipulation and self-grooming, lying activities, and less $(\mathrm{P}<0.05)$ inactivity and standing compared to when calves housed in individual and group. Vieira et al., 2010 also observed that paired calves had a shorter latency to start feeding, visited the starter feeder more frequently, spent more time at the feeder, and consumed more starter than individually housed calves.

Calves that were housed in pair and receiving high milk allowance spent more time feeding than did those housed singly and receiving the similar milk allowance (Duve et al., 2012). 
Further 2 calves/pen were more engaged in eating, drinking, chewing and ruminating more than calves in groups of 4 or 8 (Abdelfattah et al., 2013). This may be due to increased social interaction among calves in groups, which may be resulted in increased the speed of diet consumption, thereby reducing eating and drinking time. Group housed calves spent more time eating solid feeds (19.3 versus 14.4) minutes with relatively higher dry matter consumption $(399 \pm 35 \mathrm{gm}$ versus $330 \pm 33 \mathrm{gm})$ than individual housed calves (Babu et al., 2004).

Tapki, 2007 observed that group housed showed the increased proportional of playing events (12.80 vs. $2.86 \%$ ), walking (19.14 vs. $3.81 \%$ ) and grooming (8.06 vs. $4.60 \%$ ), but decreased licking objects (1.03 vs. 2.94\%), idle standing (20.73 vs. $36.29 \%)$, lying (30.19 vs. $39.53 \%$ ) and restlessness (1.69 vs. $3.47 \%$ ) compared to individual housing systems $(\mathrm{p}<0.001)$. Self-grooming and object manipulation activities were significantly higher in pair than 4-8 group housed calves (Abdelfattah et al., 2013). Latter Mahmoud and Darwish., 2018 reported that object manipulation and self-grooming activities in pair group calves were significantly higher than those kept in group. This may be due to social deprivation which may be enhanced the non-nutritive oral activities in dairy calves. In contrast to this Chua et al., (2002) observed no differences in the amount of time spent on self-grooming between individually and pairhoused calves.

The time spent for idle standing activities in individual housing were more than group housing (Babu et al., 2004). Standing activities in group were significantly higher than those recorded in pair housed (Mahmoud and Darwish., 2017). Abdelfattah et al., (2013) observed that calves housed in groups of 4 and 8 stood more compared to pairs housed calves, and this was due to availability of free space which gives an opportunity for calves to stand and walk more. This is already proposed that calves housed together in a pen moved more easily than housed in individual stalls because they can walk together around the pen and lie down close to other calves leaving space for others to remain standing (Veissier et al., 1997). But in contrast Chua et al., (2002) and Vieira et al., (2012) reported that pair-housed calves spent more time standing than individually housed calves.

Abdelfattah et al., (2013) found that calves housed in pairs observed lying more than groups contain 4 and 8 calves because of greater social interaction between calves and disturbance from pen-mates in group housed animals. Mahmoud and Darwish (2017) observed that lying behavior patterns in pair housed were significantly higher than those in individual and group housed. However, in contrast Chua et al., (2002) observed no significant differences in the lying down time between individually or pair housed calves. Whereas Babu et al., (2004) found that the time spent for sleeping/lying activities in individual housing were more than in group housing.

\section{Effect of group housing on feed intake and body weight gain of calves}

It was found that grass intake and time spent on grazing were greater for grouped calves than for individual calves (Phillips, 2004) and it was also found that raising calves in groups increased concentrate consumption and the early onset of rumination compared to individual rearing (Babu et al., 2003, 2004). Bernal- Rigoli et al., (2012) found that DMI was greater for group housed calves after 41 days of age, resulting in greater BW gains for group-housed calves. Similarly, pair housing of dairy calves has been associated with increased solid feed intake (Jensen et al., 
2015). Group housed calves increased their calf starter intake $(37.35 \pm 1.24 \mathrm{~kg}$ vs. $23.39 \pm 0.86 \mathrm{~kg} ; \mathrm{p}<0.001)$, alfalfa hay intake $(8.76 \pm 0.35 \mathrm{~kg}$ vs. $7.14 \pm 0.43 \mathrm{~kg} ; \mathrm{p}<0.05)$ and total feed intake $(46.11 \pm 1.04 \mathrm{~kg}$ vs. $30.53 \pm 0.86 \mathrm{~kg} ; \quad \mathrm{p}<0.001)$ compared to individual housed calves. Group housed calves showed increased body weight gain by about $2.36 \mathrm{~kg}$ and body length by about 1.48 $\mathrm{cm}$ per calf compared to those kept in individual pens $(\mathrm{p}<0.05)$ (Tapki, 2007).

Most recently, it was shown that pair housing of calves starting in the first week of life increased calf feed intake and weight gains compared to individual housing and pairing calves at $6 \mathrm{wk}$ of age (Costa et al., 2015). Calves that were group housed early in life, in addition to having increased solid feed intakes, also showed reduced behavioral responses to mixing and weaning (Chua et al., 2002; Vieira et al., 2012a,b). Calves reared in groups continue to get benefit from higher concentrate intake than calves previously reared individually, even after all calves are mixed in group pens at later stage (Vieira et al., 2010). Such effects that persist beyond the period of individual housing might be due to the better learning abilities of socially housed calves described above, allowing them to learn more rapidly where and how to use new feeders.

Duve et al., (2012) found that group-housed calves were faster at locating feed and spent more time eating concentrates in competitive situations than did calves that had been individually housed; these findings are consistent with the interpretation that intake differences persisting beyond the period of individual rearing are due in part to cognitive deficits.

In addition, preweaning intake of solid feed helps to improve the transition from milk to solid feed at weaning (Weary et al., 2009), such that calves that do not achieve adequate solid feed intakes before weaning experience poor growth and in Bull calves that were reared in groups also gained weight more rapidly than individually housed calves (Andrighetto et al., 1999; Xiccato et al., 2002). Other work has shown the advantages of early gains during the milk-feeding period on the later weight gains of older heifers (Bond et al., 2015). Early gains also have positive effects on the onset of puberty and milk production in the first and later lactations (Moallem et al., 2010; Soberon et al., 2012). A similar line of research has shown that Holstein bull calves reach puberty earlier and have larger testicular mass when offered a high plane of nutrition early in life (Dance et al., 2015). Thus, early growth achieved in the first weeks of life can have profound effects on production and reproduction later in life.

Pempek et al., (2016) investigated the effect of pair housing on the behavior and growth performance. They found that Calves housed in pairs tended to have greater average daily gain compared with calves housed individually $(0.63$ vs. $0.59 \pm 0.02 \mathrm{~kg} / \mathrm{d}$, respectively). Pair housing also increased final body weight compared with individual housing $(64.9$ vs. $61.7 \pm 0.59 \mathrm{~kg}$, respectively). During observation periods, calves housed individually spent more time engaging in non-nutritive sucking than calves housed in pairs ( 21.5 vs. $8.15 \pm 0.03 \%$ of total observations).

Bolt et al., (2017) assessed the effects of varying degrees of social contact on weaning stress, health and production during pen rearing, and on the social networks that calves later formed when grouped. They recorded the vocalisations as a measure of stress for three days before, during and after weaning. Vocalisations were highest post-weaning, and were significantly higher in Individual group calves than pair-reared calves. Furthermore, 
pair housed from day 28 calves vocalised significantly more than pair housed from day 5 calves. Abdelfattah et al., (2018) found that grouping at $3^{\text {rd }}, 7^{\text {th }}$ and $14^{\text {th }}$ day did not affect final $\mathrm{BW}, \mathrm{BW}$ gain, or $\mathrm{ADG}\left(F_{2}, 26=3.99, P\right.$ $>0.05)$. Average daily gain (mean $\pm \mathrm{SE}$ ) was similar among treatment groups $(0.8 \pm 0.04$, $0.7 \pm 0.04$, and $0.7 \pm 0.04 \mathrm{~kg} / \mathrm{d}$ for $\mathrm{GH} 3, \mathrm{GH} 7$, and $\mathrm{GH} 14$, respectively, $F_{2}, 27=1.02, P=$ 0.49).

\section{Effect of housing on health condition of animals}

Curtis et al., (2018) reported that during the pre-weaning phase group housed calves had a greater risk of disease occurance (diarrhoea: odds ratio 3.86 vs pneumonia: odds ratio 5.80) than individually reared calves. In contrary to above Abdelfattah et al., (2018) reported that calf fecal, cough, and nasal and ocular discharge scores, differential leukocyte counts, and plasma cortisol concentrations were not affected by age at grouping.

\section{Effect of housing on behavior and intake at time of weaning}

Overvest et al., (2018) observed that individually housed and pair-housed calves experienced behavioral changes around weaning time which includes increasing feeding time, solid feed intake, and decreasing lying time and bout frequency. In pair housed calves solid feed consumption was more than (0.96 vs. $0.50 \mathrm{~kg} / \mathrm{d}$ on $\mathrm{d} 48)$ that of the individually housed calves. Further pair-housed calves had greater feeding rates than individually housed calves (13.4 vs. $6.6 \mathrm{~g}$ of $\mathrm{DM} / \mathrm{min}$ ). As advance with calf age lying time and lying about frequency decreased during the weaning period across treatments, and pair-housed calves tended to spend less time lying than individually housed calves (1,015 vs. $1,039 \mathrm{~min} / \mathrm{d})$ during this time period. Cushon and DeVries (2016) reported that concentrate intake of paired housed calves tended $(P=0.06)$ to be higher than that of individually housed calves before weaning and during the weaning period, paired housed calves consumed more solid feed and had greater ADG. Latter on when calves were offered a choice of social noncompetitive feeding ( 2 buckets on the side with the tethered calf) or isolated feeding, previously paired housed calves preferred to spend a greater percentage of feeding time on the social side of the pen than IH calves $\left(\mathrm{F}_{1,8}\right.$ $=10.70 ; \mathrm{P}=0.011)$.

\section{References}

Abdelfattah, E. M., Schutz, M. M., Lay Jr, D. C., Marchant-Forde, J. N. and Eicher, S. D. (2013). Effect of group size on behavior, health, production, and welfare of veal calves. Journal of Animal Science, 91: 5455-5465.

Andrighetto, I., Gottardo, F., Andreoli, D. and Cozzi. G. (1999). Effect of type of housing on veal calf growth performance, behaviour and meat quality. Livest. Prod. Sci. 57: 137-145.

Babu, L. K., Pandey, H. N. and Sahoo, A. (2003). Effect of individual versus group rearing and feeding of different levels of milk and skim milk on nutrient utilization in crossbred calves. Asianaustralas. J. Anim. Sci. 16: 1455-1459.

Babu, L. K., Pandey, H. N. and Sahoo, A. (2004). Effect of individual versus group rearing on ethological and physiological response of cross-bred calves. Appl. Anim. Behav. Sci. 87: 177-191.

Bernal-Rigoli, J. C., Allen, J. D., Marchello, J. A., Cuneo, S. P., Garcia, S. R., Xie, G. and Duff, G. C. (2012). Effects of housing and feeding systems on performance of neonatal Holstein bull calves. Journal of Animal Science, 90: 2818-2825. 
Bolt, S. L., Boyland, N. K., Mlynski, D. T., James, R. and Croft, D. P. (2017). Pair housing of dairy calves and age at pairing: Effects on weaning stress, health, production and social networks. PloS one, 12(1), e0166926.

Chua, B., Coenen, E., Van Delen, J. and Weary, D. M. (2002). Effects of pair versus individual housing on the behavior and performance of dairy calves. Journal of Dairy Science, 85: 360-364.

Costa, J. H. C., Meagher, R. K., Von Keyserlingk, M. A. G. and Weary, D. M. (2015). Early pair housing increases solid feed intake and weight gains in dairy calves. Journal of Dairy Science, 98: 6381-6386.

Curtis, G., Argo, C. M., Jones, D. and GroveWhite, D. (2018). The impact of early life nutrition and housing on growth and reproduction in dairy cattle. PloS one, 13(2): 0191687.

Dance, A., Thundathil, J., Wilde, R., Blondin, P. and Kastelic, J. (2015). Enhanced early-life nutrition promotes hormone production and reproductive development in Holstein bulls. J. Dairy Sci. 98: 987-998.

Duve, L. R., Weary, D. M., Halekoh, U. and Jensen, M. B. (2012). The effects of social contact and milk allowance on responses to handling, play, and social behavior in young dairy calves. J. Dairy Sci. 95: 6571-6581.

Jensen, M. B., Duve, L. R. and Weary, D. M. (2015). Pair housing and enhanced milk allowance increase play behavior and improve performance in dairy calves. $J$. Dairy Sci. 98: 2568-2575.

Mahmoud, U. T. and Darwish, M. H. (2018). Effect of Pair Housing Versus Individual and Group Housing on Behavioural Patterns of Buffalo Calves. Journal of Advanced Veterinary Research, 8: 12-15.
Moallem, U., Werner, D., Lehrer, H., Zachut, M., Livshitz, L., Yakoby, S. and Shamay, A. (2010). Long-term effects of ad libitum whole milk prior to weaning and prepubertal protein supplementation on skeletal growth rate and first-lactation milk production. $J$. Dairy Sci., 93: 2639-2650.

Overvest, M. A., Crossley, R. E., MillerCushon, E. K. and DeVries, T. J. (2018). Social housing influences the behavior and feed intake of dairy calves during weaning. Journal of Dairy Science, 101: 8123-8134.

Pempek, J. A., Eastridge, M. L., Swartzwelder, S. S., Daniels, K. M. and Yohe, T. T. (2016). Housing system may affect behavior and growth performance of Jersey heifer calves. Journal of Dairy Science, 99: 569-578.

Phillips, C. J. C. (2004). The effects of forage provision and group size on the behavior of calves. J. Dairy Sci. 87: 1380-1388.

Soberon, F., Raffrenato, E., Everett, R. W. and Van Amburgh, M. E. (2012). Preweaning milk replacer intake and effects on long-term productivity of dairy calves. Journal of Dairy Science, 95: 783-793.

Tapki, I. 2007. Effects of individual or combined housing systems on behavioural and growth responses of dairy calves. Acta Agric. Scand. A Anim. Sci. 57: 55-60.

Veissier, I., Chazal, P., Pradel, P. and Le Neindre, P. (1997). Providing social contacts and objects for nibbling moderates reactivity and oral behaviors in veal calves. Journal of Animal Science, 75: 356-365.

Vieira, A. D. P., Von Keyserlingk, M. A. G. and Weary, D. M. (2010). Effects of pair versus single housing on performance and behavior of dairy calves before and after weaning from 
milk. Journal of dairy science, 93: 3079-3085.

Vieira, A. D. P., de Passillé, A. M. and Weary, D. M. (2012a). Effects of the early social environment on behavioral responses of dairy calves to novel events. Journal of Dairy Science, 95: 5149-5155.

Vieira, A. D. P., Von Keyserlingk, M. A. G. and Weary, D. M. (2012b). Presence of an older weaned companion influences feeding behavior and improves performance of dairy calves before and after weaning from milk. Journal of
Dairy Science, 95: 3218-3224.

Weary, D. M., Huzzey, J. M. and von Keyserlingk, M. A. G.(2009). Boardinvited review: Using behavior to predict and identify ill health in animals. J. Anim. Sci. 87: 770-777.

Xiccato, G., Trocino A., Queaque, P. I., Sartori, A. and Carazzolo, A. (2002). Rearing veal calves with respect to animal welfare: Effects of group housing and solid feed supplementation on growth performance and meat quality. Livest. Prod. Sci. 75:269-280.

\section{How to cite this article:}

Komal, Sweety, Veenesh Rajpoot and Man Singh. 2020. Effect of Housing on General Behaviour, Performance and Health of Dairy Animals-A Review. Int.J.Curr.Microbiol.App.Sci. 9(02): 2823-2828. doi: https://doi.org/10.20546/ijcmas.2020.902.321 